\title{
Pengaruh Kualitas Informasi, Kualitas Sistem Informasi, dan Perceived Usefulness pada Kepuasan Pengguna SIMDA
}

\author{
Ida Ayu Prabadewi Apsari ${ }^{1}$ \\ Fakultas Ekonomi dan Bisnis \\ Universitas Udayana, Indonesia \\ Email: idaayupraba@gmail.com
}

\author{
Ida Bagus Putra Astika² \\ Fakultas Ekonomi dan Bisnis \\ Universitas Udayana, Indonesia
}

\begin{abstract}
ABSTRAK
Penelitian ini bertujuan untuk menguji pengaruh kualitas informasi, kualitas sistem informasi dan perceived usefulness pada kepuasan pengguna sistem informasi manajemen daerah (SIMDA). Data dikumpulkan dengan menggunakan instrumen penelitian berupa kuesioner yang disebarkan kepada Kepala Subbagian Keuangan, Bendahara Penerimaan, Bendahara Pengeluaran, dan Operator SIMDA pada Pemerintah Daerah Kabupaten Badung. Teknik analisis data yang digunakan dalam penelitian ini adalah analisis regresi linear berganda. Hasil analisis menunjukkan bahwa kualitas informasi, kualitas sistem informasi, dan perceived usefulness berpengaruh positif pada kepuasan pengguna SIMDA. Dengan demikian semakin baik kualitas informasi, kualitas sistem informasi, dan perceived usefulness maka akan meningkatkan kepuasan pengguna SIMDA.
\end{abstract}

Kata Kunci: Kualitas Informasi; Kualitas Sistem Informasi; Perceived Usefulness; Kepuasan Pengguna.

\section{The Effect of Information Quality, Information System Quality, and Perceived Usefulness on SIMDA User Satisfaction}

\section{ABSTRACT}

This study aims to examine the effect of information quality, information system quality and perceived usefulness on user satisfaction of regional management information systems (SIMDA). Data are collected using research instruments in the form of questionnaires distributed to the Head of Financial Subdivision, Treasurer of Revenue, Treasurer of Expenditures, and Operators SIMDA to the Regional Government of Badung Regency. The data analysis technique used in this study is multiple linear regression analysis. The results of the analysis show that information quality, information system quality, and perceived usefulness have a positive effect on SIMDA user satisfaction. Thus, the better the quality of information, the quality of information systems, and perceived usefulness, it will increase SIMDA user satisfaction.

Keywords: Information Quality; Information System Quality; Perceived Usefulness; User Satisfaction.

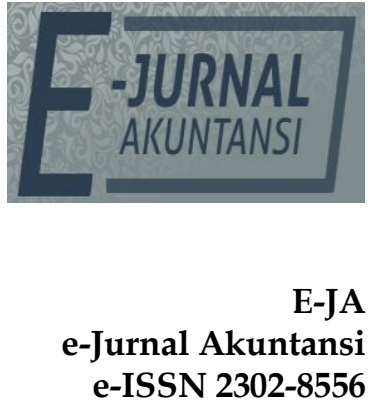

Vol. 30 No. 3

Denpasar, Maret 2020

Hal. 611-623

Artikel Masuk:

24 November 2019

Tanggal Diterima: 15 Januari 2020 


\section{PENDAHULUAN}

Penerapan SIMDA pada pemerintah daerah sebagai suatu organisasi sektor publik diharapkan dapat meningkatkan kualitas informasi akuntansi yang terkandung dalam laporan keuangan pada lingkungan pemerintah daerah tersebut. Peraturan Pemerintah Republik Indonesia Nomor 65 Tahun 2010 tentang Sistem Informasi Keuangan Daerah menjelaskan bahwa Sistem Informasi Keuangan Daerah (SIKD) adalah suatu sistem yang mendokumentasikan, serta mengolah data pengelolaan keuangan daerah dan data terkait lainnya sebagai bahan pengambilan keputusan dalam rangka perencanaan, pelaksanaan, dan pelaporan pertanggungjawaban pemerintah daerah.

Banyak penelitian telah dilakukan untuk mengidentifikasi faktor-faktor yang menyebabkan kesuksesan sistem teknologi informasi, salah satunya adalah penelitian yang dilakukan oleh Delone \& Mclean (1992). Model kesuksesan sistem informasi dari Delone \& Mclean (1992) ini merupakan model yang sederhana dan dinilai cukup valid. Seiring dengan berkembangnya penelitian mengenai sistem informasi, model yang dikembangkan oleh DeLone dan McLean ini mendapatkan berbagai kritik dan saran. Kontribusi penelitianpenelitian sebelumnya dan akibat perubahan-perubahan dari peran dan penanganan sistem informasi yang telah berkembang, maka Delone \& Mclean (2003) memperbarui modelnya dan menyebutnya sebagai Updated DEM IS Success Model.

Pengukuran keberhasilan sistem informasi, yang dalam penelitian ini yaitu SIMDA mengacu pada model kesuksesan sistem informasi yang diperbarui dari Delone \& Mclean (2003). Updated DEM IS Success Model yang dikembangkan oleh Delone \& Mclean (2003) menjelaskan bahwa terdapat tujuh faktor atau komponen dalam mengukur kesuksesan sistem informasi, antara lain kualitas sistem (system quality), kualitas informasi (information quality), kualitas pelayanan (service quality), intensi memakai (intention to use), pemakaian (use), kepuasan pemakai (user satisfaction), dan manfaat bersih (net benefits). Oleh karena SIMDA merupakan sistem keuangan daerah yang hanya digunakan pada pihak intern terkait dengan pengelolaan keuangan daerah dan tidak ada sangkut pautnya dengan kepentingan pelayanan publik, maka faktor kualitas pelayanan (service quality) tidak diikutsertakan dalam mengukur keberhasilan SIMDA.

Delone \& Mclean (2003) menjelaskan bahwa semakin tinggi kualitas sistem serta optimalnya penggunaan sistem maka pengguna akan merasa puas. Semakin baik kualitas informasi (output) yang dihasilkan dari sistem, maka semakin meningkat pula kepuasan pengguna akan penggunaan sistem karena dapat menyelesaikan pekerjaannya. Kepuasan pengguna merupakan perilaku yang muncul akibat adanya keuntungan atas pemakaian sistem informasi tersebut (Seddon \& Kiew, 1996).

Penelitian terhadap kepuasan pengguna akhir sistem informasi merupakan hal yang penting untuk mengukur kesuksesan penerapan suatu sistem informasi. Kepuasan sering digunakan sebagai proksi untuk kesuksesan sebuah sistem informasi dibandingkan dengan proksi yang lain seperti tingkat penggunaan (usage) dan persepsi mengenai manfaat (Koeswoyo, 2006). Penelitian ini dibangun berdasarkan Theory of Reasoned Action (TRA) untuk mengukur sikap dan perilaku individu terhadap kepuasan penggunaan sistem 
informasi. TRA yang dikembangkan oleh Azjen dan Fishbein (1980) adalah suatu teori yang berhubungan dengan sikap dan perilaku individu dalam melaksanakan kegiatan.

TRA diadopsi oleh Technology Acceptance Model (TAM), yaitu suatu model yang diperkenalkan oleh Davis et al., (1989) yang menjelaskan aspek keperilakuan pengguna sistem informasi. TAM adalah model yang digunakan untuk memprediksi penerimaan pengguna terhadap sistem informasi berdasarkan persepsi kemanfaatan (perceived usefulness) dan persepsi kemudahan penggunaan (perceived ease of use). Apabila pengguna melihat manfaat dan kemudahan dalam penggunaan sistem informasi akan menyebabkan tindakan pengguna tersebut dapat menerima penggunaan sistem informasi.

Davis et al., (1989) mendefinisikan kemanfaatan (usefulness) sebagai suatu tingkatan dimana seseorang percaya bahwa penggunaan suatu subyek tertentu akan dapat meningkatkan prestasi kerja orang tersebut. Perceived usefulness didefinisikan sebagai sejauh mana seseorang percaya bahwa menggunakan suatu teknologi akan meningkatkan kinerja pekerjaanya. Perceived usefulness merupakan suatu kepercayaan tentang proses pengambilan keputusan, jika seseorang merasa percaya bahwa sistem informasi berguna maka dia akan menggunakannya. Sebaliknya jika seseorang merasa percaya bahwa sistem informasi kurang berguna maka dia tidak akan menggunakannya (Jogiyanto, 2007). Sehingga dari definisi tersebut dapat diartikan bahwa kemanfaatan dari penggunaan komputer dapat meningkatkan kinerja, dan prestasi kerja orang yang menggunakannya. Rai et al., (2002) meneliti hubungan antara perceived usefulness dengan user satisfaction dengan menggunakan tiga model keberhasilan sistem informasi. Ketiga model tersebut adalah model keberhasilan sistem informasi Delone \& Mclean (1992) dan Model Seddon (1996), yang dimodifikasi dengan menambahkan hubungan antara perceived usefulness dengan system use. Hasil penelitiannya secara keseluruhan menunjukkan perceived usefulness berpengaruh terhadap user satisfaction.

Berdasarkan fenomena yang dialami Pemerintah Daerah Kabupaten Badung dalam menerapkan SIMDA dengan mengacu pada Updated DEM IS Success Model dari Delone \& Mclean (2003) membuat penelitian yang berlokasi di Pemerintah Daerah Kabupaten Badung ini menarik untuk dilakukan.

Kualitas informasi merupakan kualitas output yang berupa informasi yang dihasilkan oleh sistem informasi yang digunakan (Rai et al., 2002). Semakin tinggi kualitas informasi yang dihasilkan suatu sistem informasi, akan semakin meningkat kepuasan penggunanya (Delone \& Mclean, 2003). Ukuran kepuasan pengguna pada sistem informasi salah satunya dicerminkan dari kualitas informasi yang dihasilkan oleh suatu sistem. Kepuasan pengguna terhadap suatu sistem informasi adalah bagaimana cara pengguna sistem mamandang sistem informasi secara nyata, bukan kualitas sistem informasi secara teknik (Guimaraes et al., 1992). Jika pengguna sistem percaya bahwa informasi yang dihasilkan sistem tersebut optimal, maka merek akan merasa puas menggunakan sistem tersebut.

Penelitian Seddon \& Kiew (1996), Rai et al., (2002), Istianingsih dan Utami (2009), dan Wahyuni (2011) telah melakukan pengujian mengenai pengaruh dari kualitas informasi pada kepuasan pengguna sistem informasi. Hasil pengujian 
mereka menunjukkan bahwa kualitas informasi berpengaruh positif pada kepuasan pengguna akhir sistem informasi. Namun tidak sejalan dengan hasil penelitian Dekeng \& Rahmawati (2015), Yasa \& Ariyanto (2017) yang menunjukkan bahwa kualitas informasi tidak berpengaruh pada kepuasan pengguna. Berdasarkan uraian tersebut, maka hipotesis penelitian ini adalah sebagai berikut:

$\mathrm{H}_{1}$ : Kualitas informasi berpengaruh positif pada kepuasan pengguna.

Keberhasilan penerapan sistem informasi dipengaruhi oleh beberapa faktor, salah satu diantaranya yaitu kualitas sistem yang unggul dan bermutu. Delone \& Mclean (2003) menyatakan bahwa semakin tinggi kualitas sistem, maka informasi yang dihasilkan akan menjadi berkualitas. Pengguna sistem informasi akan merasa puas terhadap sistem informasi yang digunakan apabila mereka yakin bahwa kualitas sistem dan informasi yang dihasilkan oleh sistem tersebut baik dan dapat diandalkan dalam proses pengambilan keputusan. Kepuasan pengguna sistem informasi akan memberikan dampak peningkatan pengguna dalam menggunakan sistem informasi sehingga pengguna akan tetap menggunakan sistem informasi dalam menunjang pengelolaan keuangannya.

Kepuasan pengguna ditentukan oleh mutu sistem informasi yang mengacu pada kemudahan penggunaannya. Jika pengguna menganggap sistem informasi mudah digunakan, maka sistem informasi tersebut bisa dikatakan berkualitas. Hasil penelitian Istianingsih \& Wijayanto (2008), Istianingsih \& Utami (2009), Arifin \& Pratolo (2012), dan Dekeng \& Rahmawati (2015) memberikan bukti empiris bahwa kualitas sistem berpengaruh positif pada kepuasan pengguna. Apabila kualitas sistem informasi baik menurut persepsi penggunaannya, maka mereka akan cenderung merasa puas dalam menggunakan sistem tersebut. Berdasarkan uraian tersebut, maka hipotesis penelitian ini adalah sebagai berikut:

$\mathrm{H}_{2}$ : Kualitas sistem berpengaruh positif pada kepuasan pengguna.

Perceived usefulness merupakan suatu kepercayaan tentang proses pengambilan keputusan, jika seseorang merasa percaya bahwa sistem informasi berguna maka dia akan menggunakannya. Sebaliknya jika seseorang merasa percaya bahwa sistem informasi kurang berguna maka dia tidak akan menggunakannya (Jogiyanto, 2007). Dari pernyataan tersebut tentunya suatu kepercayaan yang baik terhadap suatu sistem informasi akan menimbulkan kepuasan pengguna sistem tersebut. Rukmiyati \& Budiarta (2016) menyatakan bahwa perceived usefulness berpengaruh positif pada kepuasan pengguna akhir sistem informasi. Kartika \& Anton (2016) juga menyatakan hal yang sama dimana perceived usefulness berpengaruh terhadap kepuasan pengguna. Fong \& Michael (2014) dalam penelitiannya juga menyatakan bahwa kepuasan pengguna didasari oleh perceived usefulness. Perceived usefulness merupakan faktor yang penting yang mempengaruhi kepuasan pengguna sistem informasi akuntansi. Dari pernyataan tersebut diatas maka hipotesis dalam penelitian ini adalah: $\mathrm{H}_{3}$ : Perceived usefulness berpengaruh positif pada kepuasan pengguna. 


\section{METODE PENELITIAN}

Penelitian ini dilakukan di Pemerintah Daerah Kabupaten Badung di Jl. Raya Sempidi, Mengwi, Badung-Bali, dengan mengamati pelaksanaan tugas Organisasi Perangkat Daerah (OPD) Kabupaten Badung. Pada penelitian ini yang menjadi obyek penelitian adalah pengaruh kualitas informasi dan kualitas sistem informasi terhadap kepuasan pengguna sistem manajemen daerah.

Populasi dalam penelitian ini berjumlah 38 Organisasi Perangkat Daerah (OPD) yang ada di Lingkungan Pemerintah Daerah Kabupaten Badung. Sampel yang diambil dalam penelitian ini berjumlah 135 responden. Adapun kriteria responden dalam penelitian ini adalah seluruh pengguna SIMDA yang terlibat dalam proses pengelolaan keuangan daerah, yang meliputi Kepala Subbagian Keuangan, Bendahara Penerimaan, dan Bendahara Pengeluaran, dan Operator SIMDA yang menggunakan SIMDA untuk dapat menghasilkan laporan keuangan OPD sebagai bentuk pertanggungjawaban kinerja.

Model yang digunakan untuk melakukan analisis data dan pengujian hipotesis dalam penelitian ini adalah model analisis regresi linier berganda.

Secara matematis bentuk persamaan regresi linier berganda adalah sebagai berikut:

$$
Y=\alpha+\beta_{1} X_{1}+\beta_{2} X_{2}+\beta_{3} X_{3}+\varepsilon
$$

Keterangan:

$\begin{array}{ll}\mathrm{Y} & : \text { Kepuasan Pengguna Sistem Manajemen Daerah (SIMDA) } \\ \mathrm{a} & : \text { Konstanta } \\ \beta 1, \beta 2, \beta 3 & : \text { Koefisien Regresi Variabel } \mathrm{X}_{1}, \mathrm{X}_{2} \text {, dan } \mathrm{X}_{3} \\ \mathrm{X}_{1} & : \text { Kualitas Informasi } \\ \mathrm{X}_{2} & : \text { Kualitas Sistem Infomasi } \\ \mathrm{X}_{3} & : \text { Perceived Usefulness } \\ \varepsilon & : \text { Error atau variabel residual }\end{array}$

\section{HASIL DAN PEMBAHASAN}

Uji normalitas ini bertujuan untuk mengetahui apakah residual dari model regresi yang dibuat berdistribusi normal atau tidak. Dalam penelitian ini uji normalitas dilakukan dengan menguji normalitas residual dengan menggunakan uji Kolmogorov-Smirnov. Jika probabilitas signifikansi nilai residual lebih besar dari 0,05 maka data tersebut dikatakan berdistribusi normal. Demikian pula sebaliknya, jika probabilitas signifikansi residual lebih rendah dari 0,05 maka data tersebut dikatakan tidak berdistribusi normal.

Tabel 1. Hasil Uji Normalitas

\begin{tabular}{ll}
\hline & Unstandardized Residual \\
\hline $\mathrm{N}$ & 135 \\
Kolmogorov-Smirnov Z & 1,610 \\
Asymp.Sig.(2-tailed) & 0,611 \\
\hline
\end{tabular}

Sumber: Data Penelitian, 2019

Berdasarkan hasil analisis uji Normalitas pada Tabel 1. didapat nilai uji Kolmogorov-Smirnov sebesar 1,610 dengan nilai signifikansi pada Asymp. Sig. (2tailed) sebesar 0,611. Nilai signifikansi 0,611 lebih dari 0,05 maka dapat disimpulkan bahwa model persamaan regresi berdistribusi normal. 
Uji multikolinearitas bertujuan untuk menguji apakah dalam satu model regresi ditemukan adanya korelasi antar variabel bebas. Model regresi yang baik adalah tidak terjadi korelasi diantara variabel bebas. Untuk mendeteksi ada atau tidaknya korelasi antar variabel bebas dapat dilihat dari nilai tolerance dan nilai variance inflation factor (VIF). Jika nilai tolerance lebih dari $10 \%$ atau VIF Kurang dari 10, maka dapat dikatakan model telah bebas dari multikolinearitas.

Tabel 2. Hasil Uji Multikoleniaritas

\begin{tabular}{llll}
\hline Variabel & Tolerance & VIF & Keterangan \\
\hline Kualitas informasi $\left(\mathrm{X}_{1}\right)$ & 0,373 & 2,684 & Bebas multikol \\
Kualitas sistem $\left(\mathrm{X}_{2}\right)$ & 0,683 & 1,464 & Bebas multikol \\
Perceived usefulness $\left(\mathrm{X}_{3}\right)$ & 0,370 & 2,703 & Bebas multikol \\
\hline
\end{tabular}

Sumber: Data Penelitian, 2019

Berdasarkan Tabel 2. dapat dilihat bahwa nilai tolerance dan VIF dari seluruh variable tersebut menunjukkan bahwa nilai tolerance untuk setiap variabel lebih besar dari $10 \%$ atau 0,1 dan nilai VIF lebih kecil dari 10 yang berarti model persamaan regresi bebas dari multikolinearitas.

Uji heteroskedastisitas ini bertujuan untuk mengetahui apakah dalam model regresi terjadi ketidaksamaan varians dari residual satu pengamatan ke pengamatan lain yang dilakukan dengan uji Glejser. Model regresi yang baik adalah yang tidak mengandung gejala heteroskedastisitas atau mempunyai varians yang homogen. Jika variabel bebas yang diteliti tidak mempunyai pengaruh signifikan atau nilai signifikansinya lebih dari 0,05 terhadap nilai absolute residual, berarti model regresi tidak mengandung gejala heteroskedastisitas. Hasil pengujian heteroskedastisitas disajikan pada Tabel 3 berikut.

Tabel 3. Hasil Uji Heteroskedastisitas

\begin{tabular}{lll}
\hline Variabel & Signifikansi & Keterangan \\
\hline Kualitas informasi $\left(\mathrm{X}_{1}\right)$ & 0,501 & Bebas heteroskedastisitas \\
Kualitas sistem $\left(\mathrm{X}_{2}\right)$ & 0,585 & Bebas heteroskedastisitas \\
Perceived usefulness $\left(\mathrm{X}_{3}\right)$ & 0,449 & Bebas heteroskedastisitas \\
\hline
\end{tabular}

Sumber: Data Penelitian, 2019

Pada Tabel 3. dapat dilihat bahwa nilai Signifikansi dari variabel kualitas informasi adalah sebesar 0,501, kemudian kualitas sistem sebesar 0,585 dan nilai signifikansi Perceived usefulness adalah sebesar 0,449. Nilai masing-masing variabel memiliki nilai yang lebih besar dari 0,05 yang berarti tidak terdapat pengaruh antara variabel bebas terhadap absolute residual. Dengan demikian, model yang dibuat tidak mengandung gejala heteroskedastisitas

Perhitungan koefisien regresi linier berganda dilakukan dengan analisis regresi melalui software SPSS 18.0 for Windows, diperoleh hasil yang ditunjukan pada Tabel 4.

Nilai konstanta 2,655 memiliki tanda positif yang menunjukkan bahwa kualitas informasi, kualitas sistem informasi, dan perceived usefulness sama dengan nol, maka pengguna merasa puas dengan data dan informasi yang didapat dari SIMDA. Nilai koefisien regresi masing-masing variabel bebas bernilai positif dengan nilai signifikansi uji $t$ kurang dari 0,05 . Hal ini menunjukkan bahwa seluruh variabel memiliki pengaruh positif yang signifikan terhadap variabel terikat. Berikut penjelasan mengenai hasil analisis regresi 
berganda, terdiri atas koefisien determinasi $\left(\mathrm{R}^{2}\right)$, uji kelayakan model (uji $\left.\mathrm{F}\right)$, dan uji hipotesis (uji t).

Tabel 4. Hasil Analisis Regresi Linier Berganda

\begin{tabular}{|c|c|c|c|c|c|}
\hline \multirow[t]{2}{*}{ Model } & \multirow{2}{*}{\multicolumn{3}{|c|}{\begin{tabular}{lll}
\multicolumn{3}{l}{ Unstandardized Coefficients Coefficients } \\
B & Std. Error & Beta \\
2655 & 1214
\end{tabular}}} & \multirow[b]{2}{*}{$\mathrm{T}$} & \multirow[b]{2}{*}{ Sig. } \\
\hline & & & & & \\
\hline \multirow{8}{*}{$\begin{array}{ll}1 & \text { (Constant) } \\
\text { Kualitas informasi } \\
\text { Kualitas sistem } \\
\text { Perceived usefulness } \\
\text { R Square } \\
\text { Adjusted R Square } \\
\text { F Statistik } \\
\text { Signifikansi Uji F }\end{array}$} & 2.655 & 1.214 & & 2.187 & .031 \\
\hline & .493 & .075 & .330 & 6.559 & .000 \\
\hline & .336 & .066 & .188 & 5.066 & .000 \\
\hline & .703 & .066 & .534 & 10.596 & .000 \\
\hline & 0,877 & & & & \\
\hline & 0,874 & & & & \\
\hline & 310,833 & & & & \\
\hline & 0,000 & & & & \\
\hline
\end{tabular}

Sumber: Data Penelitian, 2019

Berdasarkan hasil analisis regresi linier berganda seperti yang disajikan pada Tabel 4. maka dapat dibuat persamaan regresi sebagai berikut:

$$
Y=2,655+0,493 X_{1}+0,336 X_{2}+0,703 X_{3}
$$

Koefisien determinasi $\left(\mathrm{R}^{2}\right)$ digunakan untuk mengetahui dan mengukur kemampuan model dalam menerangkan variasi variabel independen. Besarnya pengaruh variabel bebas terhadap variabel terikat yang ditunjukkan oleh nilai determinasi total (Adjusted $R$ Square) pada Tabel 4. menunjukkan nilai sebesar 0,874. Nilai Adjusted R Square sebesar 0,874 mempunyai arti bahwa sebesar 87,4\% variasi kepuasan pengguna dipengaruhi oleh variasi kualitas informasi, kualitas sistem, dan perceived usefulness, sedangkan sisanya sebesar $12,6 \%$ djelaskan oleh faktor lain yang tidak dimasukkan ke dalam model.

Uji kelayakan model regresi bertujuan untuk mengetahui apakah semua variabel bebas yang diidentifikasi (kualitas informasi, kualitas sistem, perceived usefulness) tepat digunakan memprediksi kepuasan pengguna. Uji ini sering juga disebut dengan uji F. Hasil uji F yang di analisis dengan menggunakan program SPSS diperoleh nilai $F_{\text {hitung }}$ sebesar 310,833 dengan signifikansi sebesar 0,000< 0,05, maka dapat disimpulkan bahwa pada kelompok yang diuji memiliki perbedaan yang nyata (signifikan). Hasil ini mempunyai arti bahwa ada pengaruh signifikan antara kualitas informasi, kualitas sistem, dan perceived usefulness secara simultan terhadap kepuasan pengguna.

Pengaruh variabel kualitas informasi, kualitas sistem, dan perceived usefulness, terhadap kepuasan pengguna diuji dengan menggunakan Uji $t$. Kriteria pengujian untuk menjelaskan interpretasi pengaruh antar masingmasing variabel yakni apabila nilai signifikansi adalah $<0,050$ maka $\mathrm{H}_{0}$ ditolak dan $\mathrm{H}_{1}$ diterima. Sebaliknya, jika nilai signifikansi > 0,050 maka $\mathrm{H}_{0}$ diterima dan $\mathrm{H}_{1}$ ditolak. Adapun uji hipotesis masing-masing variabel akan dijelaskan sebagai berikut:

Berdasarkan hasil analisis pengaruh kualitas informasi pada kepuasan pengguna diperoleh nilai signifikasi sebesar 0,000 dengan nilai koefisien regresi yang bernilai positif sebesar 0,493. Nilai Signifikansi 0,000 $<0,050$ mengindikasikan bahwa $\mathrm{H}_{1}$ diterima. Hasil ini mempunyai arti bahwa kualitas informasi berpengaruh positif dan signifikan pada kepuasan pengguna. 
Berdasarkan hasil analisis pengaruh kualitas sistem pada kepuasan pengguna diperoleh nilai signifikansi sebesar 0,000 dengan nilai koefisien regresi yang bernilai positif sebesar 0,336. Nilai Signifikansi 0,000<0,050 mengindikasikan bahwa $\mathrm{H}_{2}$ diterima. Hasil ini mempunyai arti bahwa kualitas sistem berpengaruh positif dan signifikan pada kepuasan pengguna.

Berdasarkan hasil analisis pengaruh perceived usefulness pada kepuasan pengguna diperoleh nilai signifikansi sebesar 0,000 dengan nilai koefisien regresi yang bernilai positif sebesar 0,703. Nilai signifikansi 0,000 $<0,050$ mengindikasikan bahwa $\mathrm{H}_{3}$ diterima. Hasil ini mempunyai arti bahwa perceived usefulness berpengaruh positif dan signifikan kepuasan pengguna.

Variabel kualitas informasi memiliki nilai signifikasi sebesar 0,000 dengan nilai koefisien regresi yang bernilai positif sebesar 0,493. Nilai Signifikansi 0,000 $<0,050$ mengindikasikan bahwa $\mathrm{H}_{1}$ diterima. Hal ini membuktikan bahwa kualitas informasi yang dihasilkan SIMDA berpengaruh positif dan signifikan pada kepuasan pengguna SIMDA di Pemerintah Daerah Kabupaten Badung. Semakin baik kualitas informasi yang terkandung dalam laporan keuangan yang dihasilkan SIMDA, maka semakin tinggi kepuasan pengguna dalam menggunakan SIMDA.

Penggunaan SIMDA di Pemerintah Daerah Kabupaten Badung telah mempermudah dan mempercepat pemerintah daerah dalam penyusunan anggaran, penatausahaan dan pelaporan/pertanggungjawaban keuangan. Informasi berkualitas yang dihasilkan dari penggunaan SIMDA menjadi sebuah solusi dalam rangka meningkatkan akuntabilitas keuangan daerah. Penerapan SIMDA di Pemerintah Daerah Kabupaten Badung telah menghasilkan laporan keuangan yang menyajikan informasi keuangan yang relevan, akurat, tepat waktu dan andal. Tingginya kualitas informasi yang dihasilkan SIMDA memberikan dampak positif pada peningkatan kepuasan yang dirasakan pengguna sistem, dimana pengguna SIMDA akan merasa nyaman dalam penggunaan dan pemanfaatan sistem tersebut.

Hasil penelitian ini sejalan dengan penelitian Wahyuni (2011), Seddon \& Kiew (1996), dan Rai et al., (2002) telah melakukan pengujian mengenai pengaruh dari kualitas informasi pada kepuasan pengguna sistem informasi. Hasil pengujian mereka menunjukkan bahwa kualitas informasi berpengaruh positif pada kepuasan pengguna akhir sistem informasi.

Variabel kualitas sistem memiliki nilai signifikansi sebesar 0,000 dengan nilai koefisien regresi yang bernilai positif sebesar 0,336. Nilai Signifikansi 0,000<0,050 mengindikasikan bahwa $\mathrm{H}_{2}$ diterima. Hasil ini membuktikan bahwa kualitas SIMDA berpengaruh positif dan signifikan terhadap kepuasan pengguna SIMDA di Pemerintah Daerah Kabupaten Badung. Semakin tinggi kualitas SIMDA, maka semakin tinggi pula kepuasan yang dirasakan pengguna dalam menggunakan SIMDA.

Persepsi pengguna di Pemerintah Daerah Kabupaten Badung pada SIMDA menunjukkan bahwa SIMDA mudah dalam penggunaannya, memiliki kecepatan akses yang tinggi, fleksibel bagi pengguna dalam mengelola keuangan daerah, dan data pengguna telah terjaga keamanannya. Pengguna SIMDA juga dapat dikatakan telah merasa puas dengan kualitas dari SIMDA, dimana hal ini tercermin dari penilaian pengguna terhadap isi (content) yang ditampilkan 
SIMDA dengan lengkap, informasi yang dihasilkan SIMDA telah sesuai kebutuhan pengguna, serta kemudahan dalam penggunaannya. Kepuasan pengguna sistem informasi memberikan dampak peningkatan minat pengguna dalam menggunakan sistem informasi sehingga pengguna akan tetap menggunakan sistem informasi dalam menunjang kegiatan pengelolaan keuangannya.

Hasil penelitian ini sejalan dengan dengan penelitian Delone \& Mclean (1992), McKinney et al., (2002), Rai et al., (2002), McGill et al., (2003) yang menemukan bahwa kualitas sistem memberikan pengaruh positif pada kepuasan penggunanya.

Variabel perceived usefulness memiliki nilai signifikansi sebesar 0,000 dengan nilai koefisien regresi yang bernilai positif sebesar 0,703. Nilai signifikansi 0,000< 0,050 mengindikasikan bahwa $\mathrm{H}_{3}$ diterima. Hasil ini membuktikan bahwa perceived usefulness berpengaruh positif dan signifikan kepuasan pengguna SIMDA di Pemerintah Daerah Kabupaten Badung. Semakin tinggi perceived usefulness maka akan semakin tinggi pula kepuasan pengguna dalam menggunakan SIMDA.

Perceived usefulness menjadi ukuran kepercayaan jika suatu teknologi informasi tersebut memberikan banyak manfaat bagi penggunanya. Apabila pengguna SIMDA di Pemerintah Daerah Kabupaten Badung mempercayai bahwa SIMDA yang digunakannya bermanfaat, maka pengguna akan merasa puas dan menggunakan SIMDA tersebut secara terus menerus. Sebaliknya, jika pengguna SIMDA percaya bahwa SIMDA kurang berguna maka akan menimbulkan sikap enggan dalam menggunakan sistem tersebut.

Hasil penelitian ini sesuai dengan hasil penelitian yang dilakukan oleh Rukmiyati \& Budiarta (2016) yang menyatakan bahwa perceived usefulness berpengaruh positif pada kepuasan pengguna akhir sistem informasi. Hasil penelitian ini berarti semakin baik perceived usefulness maka akan meningkatkan kepuasan pengguna.

Penelitian ini menghasilkan simpulan mengenai bagaimana pengaruh kualitas informasi, kualitas sistem informasi, dan perceived usefulness pada kepuasan pengguna SIMDA. Penelitian ini juga membuktikan bahwa keberhasilan sistem tidak hanya ditentukan oleh faktor teknis sistem saja tetapi faktor psikologi manusia yang menggunakannya juga berperan dalam penentuan keberhasilan sistem. Faktor psikologi dapat ditambahkan pada model Delone \& Mclean (2003) untuk mengevaluasi penerapan suatu sistem. Teori penerimaan teknologi informasi (Unified Theory of Acceptanceand Use of Tecnology) dari Venkatesh et al., (2003) dapat digunakan untuk mengukur keberhasilan penerapan teknologi informasi dari segi human factor-nya.

Penelitian ini diharapkan akan memberikan kontribusi positif bagi Pemerintah Daerah Kabupaten Badung terkait dengan penggunaan SIMDA. Hasil penelitian ini juga memberikan simpulan bahwa suksesnya pengimplementasian SIMDA sangat dipengaruhi oleh kualitas informasi, kualitas SIMDA, dan perceived usefulness. Ketika pengguna SIMDA merasa bahwa kualitas sistem yang digunakan sudah baik maka akan muncul rasa ingin terus menggunakan sistem dan pada akhirnya memberikan kepuasan dalam penggunaan sistem tersebut. 
Pemerintah Daerah Kabupaten Badung tetap harus memperhatikan kualitas SIMDA apakah sudah sesuai dengan kebutuhan pengguna dalam hal pengambilan keputusan. Serta SIMDA juga sangat penting keberadaannya karena dalam perkembangan teknologi informasi, sistem ini sangat dibutuhkan dan sangat membantu pemerintah daerah dalam penyusunan anggaran dan laporan keuangan daerah agar dalam penyampaiannya tepat waktu sehingga tercipta akuntabilitas dan transparansi yang baik bagi Pemerintah Daerah Kabupaten Badung.

\section{SIMPULAN}

Kualitas informasi berpengaruh positif pada kepuasan pengguna. Pernyataan tersebut menunjukkan bahwa semakin baik kualitas informasi yang dihasilkan dari SIMDA, maka kepuasan pengguna dalam menggunakan SIMDA akan menjadi semakin meningkat. Kualitas sistem berpengaruh positif pada kepuasan pengguna. Pernyataan tersebut menunjukkan bahwa semakin baik kualitas SIMDA, maka kepuasan pengguna dalam menggunakan SIMDA akan menjadi semakin meningkat. Perceived usefulness berpengaruh positif pada kepuasan pengguna. Pernyataan tersebut menunjukkan bahwa semakin tinggi perceived usefulness maka akan semakin tinggi pula kepuasan pengguna dalam menggunakan SIMDA.

Informasi yang dihasilkan SIMDA di Pemerintah Daerah Kabupaten Badung memiliki keandalan informasi yang masih rendah. Pernyataan tersebut menunjukkan bahwa SIMDA belum secara maksimal dapat menyajikan informasi yang akurat. Saran yang dapat diberikan kepada para pengembang sistem informasi adalah agar melakukan perbaikan sistem sehingga informasi yang dihasilkan SIMDA mampu memberikan informasi yang akurat dan dapat dipercaya oleh para pengguna sistem dan pengguna informasi dalam proses pengambilan keputusan. Pemerintah Daerah Kabupaten Badung dalam mengimplementasikan SIMDA perlu menyelenggarakan pengembanganan kualitas pengguna dengan cara pelatihan-pelatihan SIMDA agar dapat meningkatkan kinerja pegawai, sehingga terjadi peningkatan sikap penerimaan SIMDA yang dimplementasikan oleh pengguna. Kepuasan pengguna SIMDA di Pemerintah Daerah Kabupaten Badung terkait isi (content) informasi yang dihasilkan SIMDA tergolong masih belum lengkap. Para pengembang sistem informasi disarankan agar melakukan perbaikan agar informasi dari SIMDA dapat dihasilkan secara lengkap dan transparan. Penelitian selanjutnya dapat mengembangkan dengan meneliti pada lingkup yang lebih luas misalnya dengan menggunakan sampel yang lebih luas bukan hanya pada satu kabupaten tetapi beberapa kabupaten sehingga hasil penelitiaan yang diperoleh dapat dipakai untuk menggeneralisir kondisi pemerintah daerah di Indonesia secara keseluruhan.

\section{REFERENSI}

Amalia, M. S., \& Pratomo, D. (2016). Pengaruh Kualitas Sistem Informasi, Kualitas Informasi dan Perceived Usefulness Terhadap Kepuasan Pengguna Sistem Informasi Akuntansi (Studi Pada Pengguna Sistem Informasi Akuntansi di Rumah Sakit Mata Cicendo Bandung), 3(2), 1516-1522. 
Ajzen, I., \& Fishbein, M. (1980). Understanding Attitudes and Predicting Social Behavior. Englewood Cliffs, NJ: Prentice-Hall.

Arifin, F., \& Pratolo, S. (2012). Pengaruh Kualitas Sistem Informasi Keuangan Daerah Terhadap Kepuasan Aparatur Pemerintah Daerah Menggunakan Model DeLone dan McLean. Jurnal Akuntansi E Investasti. 13(1), 28-34.

Buana, M. M. I. B. G., \& Wirawati, N. G. P. (2018). Pengaruh Kualitas Sistem Informasi, Kualitas Informasi, dan Perceived Usefulness pada Kepuasan Pengguna Sistem Informasi Akuntansi. E-Jurnal Akuntansi Universitas Udayana, 22(1), 683-713.

Chin, W. C., \& Todd, P. A. (1989). On the Use, Usefulness and Ese of Use of Structural Equation Modelling in MIS Research: A Note of Caution. MIS Quarterly, 19(2), 237-246.

Davis, F. D., Bagozzi, R. P., \& Warshaw, P. R. (1989). User Acceptance of Computer Technology: A Comparison of Two Theoretical Models. Management Science, 35(8), 982-1003. https://doi.org/10.1287/mnsc.35.8.982

Dekeng, S., \& Rahmawati, D. (2015). Pengaruh Kualitas Informasi dan Kualitas Sistem Informasi terhadap Kepuasan serta Kinerja Pengguna Sistem Informasi. Jurnal Bisnis dan Ekonomi, 6(1), 47-59.

Delone, W., \& Mclean, E. (1992). Information Systems Success: The Quest for the Dependent Variable. (October 2014). https:// doi.org/10.1287/isre.3.1.60

Delone, W., \& Mclean, E. (2003). The DeLone and McLean Model of Information Systems Success: A Ten-Year Update. (April). https:/ / doi.org/10.1080/07421222.2003.11045748

Doll, W. J., \& Torkzadeh, G. (1988). The Measurement of End-User Computing, Satisfaction. MIS Quarterly, 12(2), 259-274

Fong, S. C. C., \& Michael, W. H. Ho. (2014). Accounting Information Systems End-User Satisfaction: Evidence of Hong Kong Housing Authority. The International Technology Management Review, 4(1), 27. https:// doi.org/10.2991/itmr.2014.4.1.3

Guimaraes, T., Igbaria, M., \& Lu, M. (1992). The Determinants of DSS Success: An Integrated Model. Decision Sciences, 23(2), 409-430. https://doi.org/10.1111/j.1540-5915.1992.tb00397.x

Istianingsih \& Utami, W. (2009). Pengaruh Kepuasan Pengguna Sistem Informasi terhadap Kinerja Individu (Studi Empiris pada Ppengguna Paket Pprogram Aplikasi Sistem Informasi Akuntansi di Indonesia), Seminar Nasional Akuntansi XII Fakultas Ekonomi UI.

Istianingsih \& Wijanto, D. S. H. (2008). Pengaruh Kualitas Sistem Informasi, Informasi terhadap Kepuasan Pengguna Akhir Software Akuntansi (Pascasarjana Ilmu Akuntansi Fakultas Ekonomi Universitas Indonesia), Simposium Nasional Akuntansi (SNA) Ke XI Pontianak, 23-24.

Jogiyanto, H. M. (2007). Model Kesuksesan Sistem Teknologi Informasi. Yogyakarta: Andi.

Kartika, N. D., \& Anton. (2016). Analisis Kualitas Sistem Informasi, Perceived Usefulness dan Kualitas Informasi terhadap Kepuasan End User Software Akuntansi. Simposium Nasional Akuntansi XIX, Lampung, 1-21. 
Koeswoyo, G. F. (2000). Faktor-Faktor Yang Mempengaruhi Kepuasan Pemakai Software Akuntansi (Studi Empiris Pada Perusahaan Pemakai Software Akuntansi K-System Di Pulau Jawa). 1-11.

Liu, C., \& Arnett, K. P. (2000). Exploring the factors associated with Web site success in the context of electronic commerce. Information and Management, 38(1), 23-33. https:// doi.org/10.1016/S0378-7206(00)00049-5

Livari, J. (2005). An Empirical Test of the DeLone-McLean Model of Information System Success. Data Base for Advances in Information Systems, 36(2), 8-27. https://doi.org/10.1145/1066149.1066152

McGill, T., Hobbs, V., \& Klobas, J. (2003). User-developed applications and information systems success: A test of DeLone and McLean's model. Information Resources Management Journal, 16(1), 24-45. https:// doi.org/10.4018/irmj.2003010103

McKinney, V., Yoon, K., \& Zahedi, F. (2002). The measurement of Web-customer satisfaction: An expectation and disconfirmation approach. Information Systems Research, 13(3), 296-315. https://doi.org/10.1287/isre.13.3.296.76

Penny, K. L. (2014). Membumikan Transparansi dan Akuntabilitas Kinerja Sektor Publik: Tantangan Berdemokrasi ke Depan. Jakarta Gramedia Widiasarana Indonesia.

Peraturan Pemerintah Republik Indonesia Nomor 65 Tahun 2010 tentang Perubahan atas Peraturan Pemerintah Nomor 56 Tahun 2005 tentang Sistem Informasi Keuangan Daerah.

Pitt, W., \& Kavan. (1995). Service Quality: A Measure of Information System Effectiveness. MIS Quarterly, 19(2), 173-187.

Rai, A., Lang, S. S., \& Welker, R. B. (2002). Assessing the validity of IS success models: An empirical test and theoretical analysis. Information Systems Research, 13(1), 50-69. https://doi.org/10.1287/isre.13.1.50.96

Rukmiyati, S. N. M., \& Budiartha, I. K. (2016). Pengaruh Kualitas Sistem Informasi, Kualitas Informasi, dan Perceived Usefulness pada Kepuasan Pengguna Akhir Software Akuntansi (Studi Empiris pada Hotel Berbintang di Provinsi Bali). E-Jurnal Ekonomi dan Bisnis Universitas Udayana. 5(1), 115142.

Seddon, P., \& Kiew, M. Y. (1996). A Partial Test and Development of Delone and Mclean's Model of IS Success. Australasian Journal of Information Systems, 4(1), 90-109. https://doi.org/10.3127/ajis.v4i1.379

Setyo, D., \& Rahmawati, A, D. (2015). Pengaruh Kualitas Informasi dan Kualitas Sistem Informasi terhadap Kepuasan serta Kinerja Pengguna Sistem Informasi. EFEKITIF Jurnal Bisnis dan Ekonomi, 6(1), 47-59.

Venkatesh, V., Morris, M. G., Davis, G. B., \& Davis, F. D. (2003). User acceptance of information technology: Toward a unified view. MIS Quarterly: Management Information Systems, 27(3), 425-478. https://doi.org/10.2307/30036540

Wahyuni, T. (2011). Uji Empiris Model DeLone \& McLean terhadap Kesuksesan Sistem Informasi Manajemen Daerah (SIMDA). Jurnal BPPK, 2, 4-24.

Wirahutama, G. (2011). Ambiguitas Peran sebagai Variabel Moderasi terhadap Hubungan antara Kualitas Sistem Informasi dan Kepuasan Pengguna 
Software Akuntansi pada DPKAD Kota Semarang. Skripsi. UNDIP, Semarang.

Yasa, S. E. I. W., \& Ariyanto, D. (2017). Analisis Kesuksesan Sistem Informasi Manajemen Daerah dengan Mengadopsi Model DeLone \& McLean. E-Jurnal Akuntansi Universitas Udayana, 18(3), 2505-2533 